\title{
Communication
}

\section{Antitumour activity of Salmonella typhimurium VNP20047 in B16(F10) murine melanoma model ${ }^{*}$}

\author{
Joanna Jazowiecka-Rakus ${ }^{\bowtie}$ and Stanisław Szala \\ Department of Molecular Biology, Centre of Oncology, Maria Sktodowska-Curie \\ Memorial Institute, Gliwice, Poland
}

Received: 02 March, 2004; revised: 23 April, 2004; accepted: 27 April, 2004

Key words: cancer gene therapy, Salmonella, tumour targeting, cytosine deaminase

\begin{abstract}
A tumour therapy is proposed based on attenuated Salmonella typhimurium VNP20047 expressing the Escherichia coli cytosine deaminase gene. VNP20047 was administered intravenously to B16(F10) melanoma-bearing $\mathrm{C} 57 \mathrm{BL} / 6$ mice. VNP20047 proliferated within tumours and livers regardless of the initial inoculum dose. After 10 days the number of bacteria increased in livers up to $4.2 \times 10^{6} \mathrm{cfu} / \mathrm{g}$ and decreased in tumours down to $5.9 \times 10^{6} \mathrm{cfu} / \mathrm{g}$. VNP20047 at $1 \times 10^{5} \mathrm{cfu} / \mathrm{mouse}$, when combined with 5 -fluorocytosine, inhibited tumour growth by $85 \%$ without prolonging animal survival. Histology studies revealed severe lesions in tumours and livers. These data suggest that $S$. typhimurium VNP20047 induced inflammatory responses, even though the strain was attenuated.
\end{abstract}

Delivery of therapeutic genes to tumour site remains a major problem of cancer gene therapy (Greco et al., 2002). To overcome this problem various vectors (replication-defective viruses, cationic liposomes, etc.) as well as physical methods such as electroporation or gene gun, have been tried but either their selectivity or efficacy are low.

Novel strategies to deliver a high dose of therapeutic agents to tumour cells are thus investigated. One example of such a novel approach is the use of anaerobic bacteria. Bacte-

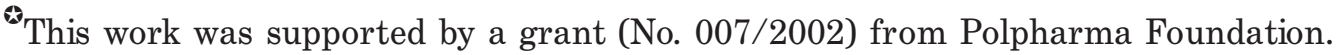

${ }^{凶}$ Corresponding author: Joanna Jazowiecka-Rakus, Department of Molecular Biology, Centre of Oncology, Maria Skłodowska-Curie Memorial Institute, Wybrzeże Armii Krajowej 15, 44-101 Gliwice, Poland; tel.: (48 32) 278 9727; fax: (48 32) 231 3512; e-mail: jjazowiecka@io.gliwice.pl

Abbreviations: cfu, colony forming units; FBS, fetal bovine serum; 5-FC, 5-fluorocytosine; 5-FU, 5-fluorouracil; i.p., intraperitoneal; i.v., intravenous; LB agar, Luria Bertani agar; $\mathrm{PBS}^{-}$, phosphate-buffered saline without $\mathrm{Mg}^{2+}$ and $\mathrm{Ca}^{2+}$.
} 
rial vectors including Clostridium, Bifidobacterium and Salmonella have been known to specifically accumulate and replicate within tumours (Yazawa et al., 2000; Theys et al., 2001; Bermudes et al., 2001). They can cause tumour cell death as a result of competing for nutrients with cancer cells and/or secreting therapeutic proteins (King et al., 2002, Theys et al., 2003). The problem with bacteriolytic therapy is its toxicity. Even after deleting the genes that induce immune response, bacteriolytic therapy led to marked mortality in mice (Dang et al., 2001).

Salmonella typhimurium strain VNP20047 carries deletions in the $m s b B$ and purI loci, which results in diminished virulence. The purI deletion creates a requirement for an external purine source for survival (Pawelek et $a l .$, 1997). The deletion of the $m s b B$ gene reduces the toxicity associated with lipopolysaccharide through preventing the addition of the terminal myristyl group to the lipid A domain (Low et al., 1999). Additionally, cytosine deaminase gene from Eschericha coli was incorporated into $S$. typhimurium VNP20047 to enhance its tumouricidal effect upon subsequent i.p. administration of 5-fluorocytosine (King et al., 2002). The inserted suicide gene converts the nontoxic 5-fluorocytosine (5-FC) to a highly toxic drug, 5-fluorouracil (5-FU). Its metabolites ultimately interfere with DNA and RNA synthesis (Bermudes et al., 2001).

The aim of our study was to investigate if attenuated $S$. typhimurium VNP20047 strain carrying $E$. coli cytosine deaminase gene localised specifically in B16(F10) murine melanoma tumours causing inhibition of its growth and improved animals survival.

\section{MATERIALS AND METHODS}

Cell culture. B16(F10) murine melanoma cell line was cultured in RPMI 1640 medium supplemented with $10 \%$ fetal bovine serum (FBS) (GibcoBRL), at $37^{\circ} \mathrm{C}$ and under $5 \%$ $\mathrm{CO}_{2}$.
Animals. Six- to eight-week-old C57BL/6 mice were bred and maintained at the on-site animal facility. Consent for experiments involving animals was obtained from the appropriate local Ethics Committee (Medical Academy, Warszawa, Poland).

B16(F10) tumours. C57BL/6 mice had their dorsal side shaved and were inoculated subcutaneously with $2 \times 10^{5}$ B16(F10) melanoma cells $100 \mu \mathrm{lBSS}^{-}$per animal.

Preparation of $S$. typhimurium VNP20047. VNP20047 bacteria were obtained from Vion Pharmaceuticals, Inc. Cultures were grown overnight at $37^{\circ} \mathrm{C}$ in $\mathrm{LB}$ broth, then centrifuged for $5 \mathrm{~min}$ at $4000 \mathrm{rpm}$, and the pellet washed twice in $2 \mathrm{ml} \mathrm{PBS}^{-}$. Bacterial suspension was appropriately diluted in PBS $^{-}$before making the dilution for injection $\left(1 \mathrm{~A}_{600}=1 \times 10^{9} \mathrm{cfu} / \mathrm{ml}\right)$ (Zheng et al., 2000). Actual dose was determined by plating appropriate solutions on LB agar plates and counting colonies after overnight incubation.

Quantitation of S. typhimurium VNP20047 accumulation. Ten days after melanoma cell injection the mice were injected with three different doses of VNP20047 $(1 \times$ $10^{4}, 1 \times 10^{5}$ and $1 \times 10^{6} \mathrm{cfu}$ ) in $0.2 \mathrm{ml} \mathrm{PBS}^{-}$ were tail-injected into tumour-bearing mice. The mice were sacrificed at different times after the injection. Tumours and livers were aseptically weighed and homogenised in PBS $^{-}$. Serial dilutions were performed to count the number of bacteria per gram of tissue.

Antitumour activity of $S$. typhimurium VNP20047. When B16(F10) tumours reached approx. $150 \mathrm{~mm}^{3}$, seven days after inoculation with the tumour cells, the mice were divided into four groups of five animals each. Group 1 consisted of mice injected with B16(F10) melanoma cells only. Group 2 received $\mathrm{PBS}^{-}(0.2 \mathrm{ml})$. Groups 3 and 4 received VNP20047 at $1 \times 10^{5} \mathrm{cfu}$ per mouse. Groups 2 and 3 received two intraperitoneal injections of 5-FC daily at a dose of $300 \mathrm{mg} / \mathrm{kg}$ on days 10 through 19 . Tumour dimensions were measured three times a week and their vol- 
ume calculated from the following formula: width $^{2} \times$ length $\times 0.52$. Tumour volume is reported as mean \pm standard deviation. The results were analysed with Student's $t$-test.

Histological analysis. To observe potential side-effects of the therapy in the treated mice, 10 days after injection of bacteria, livers and tumours were fixed in $10 \%$ neutral buffered formalin solution and embedded in paraffin. Sections, $8 \mu \mathrm{m}$-thick, were stained with hematoxylin and eosin (H\&E).

\section{RESULTS}

\section{Localization of VNP20047 bacteria in tu- mour and liver}

$\mathrm{C} 57 \mathrm{Bl} / 6$ mice that had been inoculated with B16(F10) melanoma cells were intravenously administered different doses of VNP20047. Tumour and liver samples, obtained four days after bacteria injection, were evaluated for the presence of $S$. typhimurium. Figure 1 shows that similar levels of accumulation were achieved regardless of the initial inoculum size. The dose of $10^{5} \mathrm{cfu} /$ mice was chosen for subsequent experiments.

The accumulation of VNP20047 was evaluated in tissues at specified times after injec-

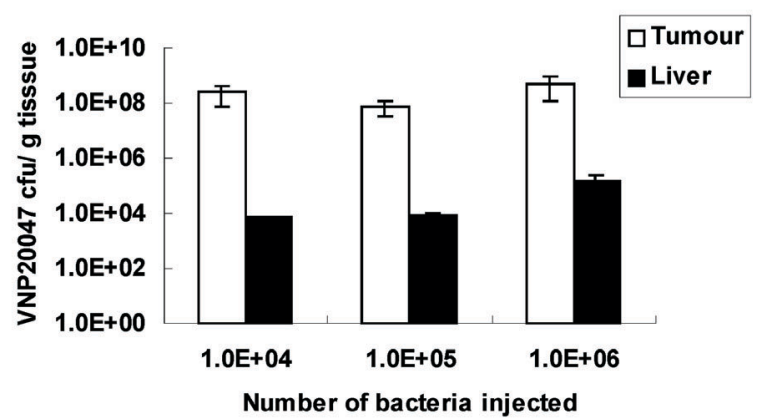

Figure 1. Accumulation of bacteria in tissues of C57BL/6 mice bearing B16(F10) melanoma injected i.v. various dose of VNP20047.

On the tenth day mice were administered different doses of VNP20047 $\left(1 \times 10^{4}, 1 \times 10^{5}\right.$ and $\left.1 \times 10^{6} \mathrm{cfu}\right)$. After subsequent four days the tumours and livers were collected, weighed and homogenised in $\mathrm{PBS}^{-}$. Bacteria were counted by plating serial dilutions of the homogenates. tion of bacteria. Figure 2 shows that at $2 \mathrm{~h}$ after injection VNP20047 accumulated in livers at nearly the same levels as in B16(F10) melanoma tumours. The number of VNP20047 bacteria increased in tumours and decreased in livers within $24 \mathrm{~h}$ after administration. By day 4 the number of VNP20047 in tumours increased significantly and the tumour-to-liver ratio amounted to $1000: 1$ on average. However, the levels of VNP20047 did not remain stable. Ten days after injection the number of bacteria increased in livers and decreased in tumours, reaching in both tissues the same level approx. $5 \times 10^{6} \mathrm{cfu} / \mathrm{g}$ tissue.

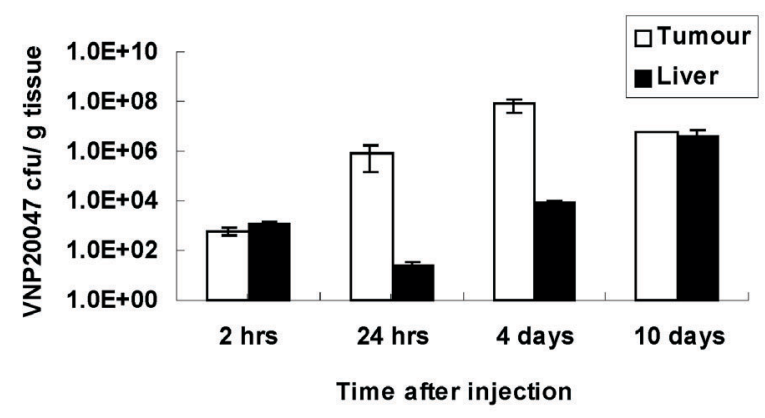

Figure 2. Colonisation of B16(F10) tumours and livers by VNP20047 following a single i.v. injection into $\mathrm{C57 \textrm {BL } / 6}$ tumour-bearing mice.

On the tenth day mice were administered a single dose of VNP20047 $\left(1 \times 10^{5} \mathrm{cfu} /\right.$ mouse $)$. The tumours and livers were collected at various time points, weighed and homogenised in $\mathrm{PBS}^{-}$. Bacteria were counted by plating serial dilutions of the homogenates.

\section{Antitumour efficacy of VNP20047}

Subcutaneous B16(F10) tumours were induced in $\mathrm{C} 57 \mathrm{Bl} / 6$ mice by injecting $2 \times 10^{5}$ viable tumour cells. Seven days later, when the tumours were about 4-5 $\mathrm{mm}$ in diameter, $10^{5}$ cfu of $S$. typhimurium VNP20047, or $\mathrm{PBS}^{-}$ (control), was injected intravenously. On the tenth day, three days after bacteria injection, the animals received intraperitoneally 300 $\mathrm{mg} / \mathrm{kg}$ of the 5 -FC prodrug per dose, twice a day for ten consecutive days. Tumour growth and survival were evaluated (Fig. $3 \mathrm{~A}$ and B). In the group treated with VNP20047/5-FC, all tumours showed $85 \%$ inhibition of growth 
during the second week of treatment. The tumours in the VNP20047 group (without 5-FC) were also significantly smaller than those in the control groups (70\% inhibition).

Nevertheless, despite the significant tumour growth inhibition, the treatment with bacteria and 5-FC did not prolong mice survival, as compared to control groups (Fig. 3B). Five independent experiments were carried out with similar results.

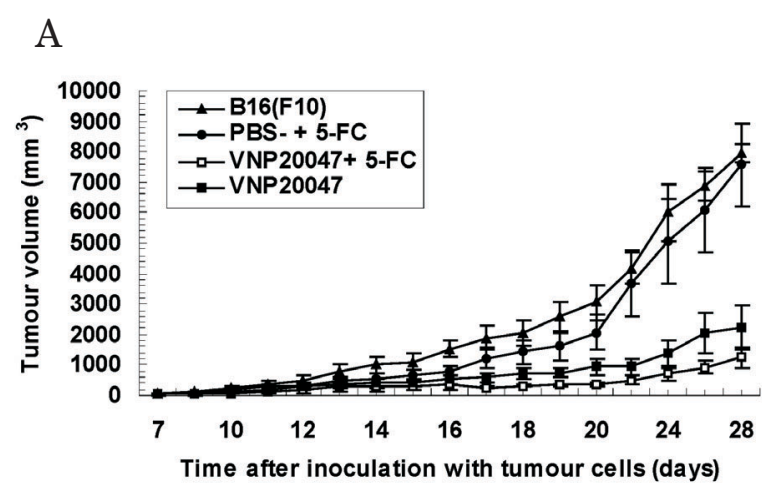

B

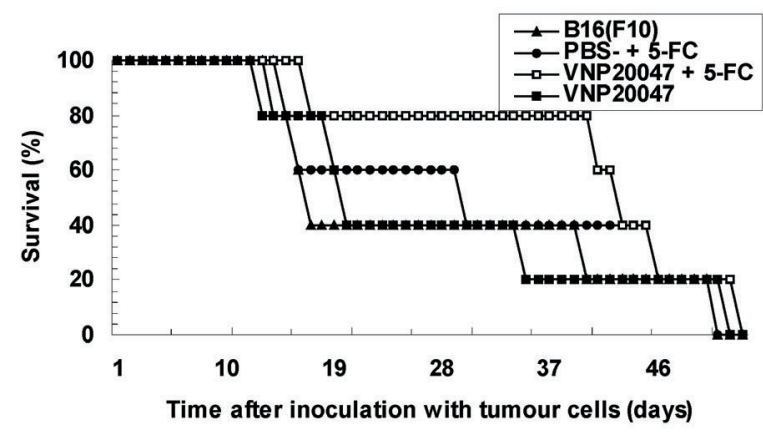

Figure 3. Antitumour effect of VNP20047 injection in $B 16(F 10)$ melanoma tumour-bearing C57BL/6 mice. (A) Average tumour growth rate and (B) mice survival.

On the seventh day mice were administered a single dose of VNP20047 $\left(1 \times 10^{5} \mathrm{cfu} /\right.$ mouse $)$ expressing cytosine deaminase gene. On days 10 through 19 mice received i.p. twice a day $300 \mathrm{mg} / \mathrm{kg}$ of 5-FC.

Histology analysis of tumours and livers in mice receiving VNP20047

Livers and spleens of mice treated with VNP20047 and examined after ten days were grossly enlarged and swollen (hepatosplenomegaly). Numerous grey-white lesions were visible in the liver. Histology sections of tu- mours and livers showed significant differences between control animals and mice treated with the attenuated Salmonella VNP20047. Ten days following the injection of bacteria several necrotic regions with surrounding inflammation were visible in the tumours (Fig. 4A). Tumours from control ani-
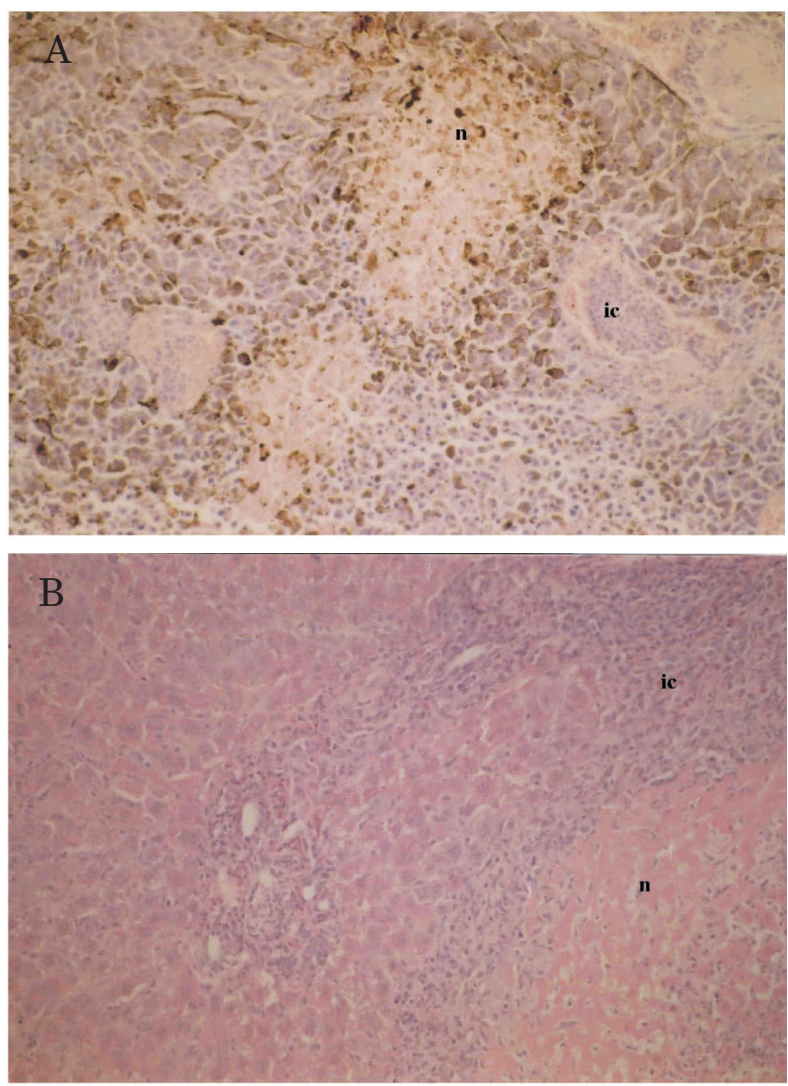

Figure 4. Histology of murine tumours and livers ten days after treatment with VNP20047 (H \& E, $200 \times$ ).

(A) Tumour and (B) liver after treatment with VNP20047. n, necrosis; ic, inflammatory cells.

mals showed less necrotic zones that also had no significant inflammatory infiltrate. Sections of livers from treated animals showed numerous inflammatory foci localised mainly centrolobularly as well as several necrotic regions (Fig. 4B).

\section{DISCUSSION}

Salmonella are Gram-negative bacteria from the Enterobacteriacea family. They are faculta- 
tive anaerobes and grow readily in simple culture media, under both aerobic and anaerobic conditions. All the bacteria from the Salmonella genus are considered potential pathogens since they cause gastroenteritis in most animal species. S. typhimurium has several advantages that enable it to exert an antitumour effect (King et al., 2000). It is able to grow in hypoxic or necrotic areas that occur in many kinds of tumours. It is capable of invading and killing host cells and is highly sensitive to many antibiotics (Luo et al., 2001). Salmonella can be easily engineered in the laboratory to express foreign genes as well as to attenuate its pathogenicity (Sznol et al., 2000). Pawelek et al. (1997) reported that attenuated Salmonella preferentially accumulated in tumour tissue of B16(F10) melanoma and M019 lung carcinoma-bearing mice with the tumour-to-liver ratio amounting to 1000:1 on average. The results obtained in those studies provided the basis for Phase I clinical trial (Toso et al., 2002).

The attenuated $S$. typhimurium VNP20047, carrying deletions of the $m s b B$ and purI genes, was developed as a vector suitable for tumour-selective delivery of therapeutic proteins (Pawelek et al., 1997). Available data suggested that tumour-targeting Salmonella could be used selectively to deliver a prodrug-converting enzyme to tumours, producing therapeutic effects (King et al., 2002). Our studies demonstrate that $S$. typhimurium VNP20047 localises not only to melanoma tumours but also to livers. Quantitative analysis demonstrated rapid growth of the bacteria in tumours within a few days after injection of VNP20047, but ultimately their number did not remain stable. After 10 days the number of bacteria decreased in the tumours and increased in livers, reaching approx. $5 \times 10^{6}$ $\mathrm{cfu} / \mathrm{g}$ of either tissue. A single dose $\left(1 \times 10^{5}\right.$ cfu/ mouse) of VNP20047, together with a systemically administered prodrug (5-FC), inhibited tumour growth but did not prolong mice survival as compared to control groups. In most cases mice treated with VNP20047 died before the onset of progressive tumour growth.

The premature death of treated mice could be caused by an excessive accumulation of the bacteria in normal tissues, resulting in inflammation foci and greatly expanded areas of necrosis. Our data suggest that $S$. typhimurium VNP20047 induced inflammatory responses, even though the strain was attenuated. These results indicate that cancer therapy using VNP20047 as a tumour selective vector is not very effective. Although the definite causes of for the death of the treated animals are not clear, additional modifications of the bacteria seem necessary to develop a still safer strain.

Authors thank Dr. A. Sochanik for helpful review of the manuscript; Dr. S. KrzyzowskaGruca and Dr. E. Malusecka for their help with microscopic analysis.

\section{R E F E R E N C E S}

Bermudes D, Low KB, Pawelek J, Feng M, Belcourt M, Zheng LM, King I. (2001) Tumor-selective Salmonella-based cancer therapy. Biotechnol Genet Eng Rev.; 18: 219-33.

Dang LH, Bettegowda C, Huso DL, Kinzler KW, Vogelstein B. (2001) Combination bacteriolytic therapy for the treatment of experimental tumors. Proc Natl Acad Sci USA.; 98: 15155-60.

Greco O, Scott SD, Marples B, Dachs GU. (2002) Cancer gene therapy; Delivery, delivery, delivery. Front Biosci.; 7: 1516-24.

King I, Luo X, Feng M, Ittensohn M, Li Z, Belcourt M, Lin S, Le T, Pike J, Troy K, Sznol M, Clairmont C, Bermudes D, Zheng LM. (2000) Tumour therapy using Salmonella. Emerging Drugs.; 5: 211-9.

King I, Bermudes D, Lin S, Belcourt M, Pike J, Troy K, Le T, Ittensohn M, Mao J, Lang W, Runyan JD, Luo X, Li Z, Zheng LM. (2002) Tumor-targeted Salmonella expressing cyto- 
sine deaminase as an anticancer agent. Hum Gene Ther.; 13: 1225-33.

Low KB, Ittensohn M, Le T, Platt J, Sodi S, Amoss M, Ash O, Carmichael E, Chakraborty A, Fischer J, Lin SL, Luo X, Miller SI, Zheng LM, King IC, Pawelek JM, Bermudes D. (1999) Lipid A mutant Salmonella with suppressed virulence and $\mathrm{TNF} \alpha$ induction retain tumor-targeting in vivo. Nat Biotechnol.; 17: 37-41.

Luo X, Li Z, Lin S, Le T, Ittensohn M, Bermudes D, Runyab JD, Shen S, Chen J, King IC, Zheng LM. (2001) Antitumor effect of VNP20009, an attenuated Salmonella, in murine tumor models. Oncol Res.; 12: $501-8$.

Pawelek JM, Low KB, Bermudes D. (1997) Tumor-targeted Salmonella as a novel anticancer vector. Cancer Res.; 57: 4537-44.

Sznol M, Lin SL, Bermudes D, Zheng LM, King IC. (2000) Use of prefentially replicating bacteria for the treatment of cancer. $J$ Clin Invest.; 105: 1027-30.

Toso JF, Gill VJ, Hwu P, Marincola FM, Restifo NP, Schwartzentruber DJ, Sherry RM, Tapalian SL, Yang JC, Stock F, Freezer LJ, Morton KE, Seipp C, Haworth L,
Mavroukakis S, White D, MacDonald S, Mao J, Sznol M, Rosenberg SA. (2002) Phase I study of intravenous administration of attenuated Salmonella typhimurium to patients with metastatic melanoma. J Clin Oncol.; 20: $142-52$.

Theys J, Landuyt AW, Nuyts S, Van Mellaert L, Lambin P, Anne J. (2001) Clostridium as a tumor-specific delivery system of therapeutic proteins. Cancer Detect Prev.; 25: 548-57.

Theys J, Barbe S, Landuyt W, Nuyts S, Van Mellaert L, Wouters B, Anne J, Lambin P. (2003) Tumor-specific gene delivery using genetically engineered bacteria. Curr Gene Ther.; 3: 207-21.

Yazawa K, Fujimori M, Amano J, Kano Y, Taniguchi S. (2000) Bifidobacterium longum as a delivery system for cancer gene therapy: selective localization and growth in hypoxic tumors. Cancer Gene Ther.; 7: 269-74.

\section{Zheng LM, Luo X, Feng M, Li Z, Le T,} Ittensohn M, Trailsmith M, Bermudes D, Lin SL, King IC. (2000) Tumor amplified protein expression therapy: Salmonella as a tumorselective protein delivery vector. Oncol Res.; 12: $127-35$. 